\title{
Publisher Correction to Volume 1 Issue 1-3
}

\section{Springer International Publishing}

Published online: 6 July 2018

(C) Springer International Publishing AG, part of Springer Nature 2018

\section{Correction to: $\mathbf{J}$ well-being assess (2017) 1:1-96}

https://doi.org/10.1007/s41543-018-0009-x

https://doi.org/10.1007/s41543-017-0001-x

https://doi.org/10.1007/s41543-017-0002-9

https://doi.org/10.1007/s41543-017-0003-8

https://doi.org/10.1007/s41543-018-0004-2

https://doi.org/10.1007/s41543-018-0005-1

https://doi.org/10.1007/s41543-018-0006-0

Due to some technical problem related with rendering of online issue 3, the below articles need to be read as part of Vol. 1, multiple Issue 1-3

\section{Editorial}

1. $10.1007 / \mathrm{s} 41543-018-0009-\mathrm{x}$

Brdar

1-7

Original Research

2. $10.1007 / \mathrm{s} 41543-017-0001-\mathrm{x}$

Schaufeli

9-24

3. $10.1007 / \mathrm{s} 41543-017-0002-9$

Jiang

25-34

4. $10.1007 / \mathrm{s} 41543-017-0003-8$

Macdougall

$35-47$

Brief Report

5. 10.1007/s41543-018-0004-2

Chang

$49-56$

Original Research

6. 10.1007/s41543-018-0005-1

Shankar

$57-75$

7. $10.1007 / \mathrm{s} 41543-018-0006-0$

Proyer

$77-96$

The online version of the original article can be found at https://doi.org/10.1007/s41543-018-0009-x; https://doi. org/10.1007/s41543-017-0001-x; https://doi.org/10.1007/s41543-017-0002-9; https://doi.org/10.1007/s41543017-0003-8; https://doi.org/10.1007/s41543-018-0004-2; https://doi.org/10.1007/s41543-018-0005-1; https:/doi. org/10.1007/s41543-018-0006-0 